\title{
Surfactants with aromatic headgroups for optimizing properties of graphene/natural rubber latex composites (NRL): Surfactants with aromatic amine polar heads
}

\author{
Tretya Ardyani, Azmi Mohamed, Suriani Abu Bakar, Masanobu \\ Sagisaka, Yasushi Umetsu, Mohamad Hafiz Mamat, \\ Mohd Khairul Ahmad, H.P.S. Abdul Khalil, Stephen King, \\ Sarah E. Rogers and Julian Eastoe
}

\section{Published version information}

Citation: T Ardyani et al. "Surfactants with aromatic headgroups for optimizing properties of graphene/natural rubber latex composites (NRL): Surfactants with aromatic amine polar heads." Journal of Colloid and Interface Science, vol. 545 (2019): 184-194.

DOI: $10.1016 /$ j.jcis.2019.03.012

(C)2019. This manuscript version is made available under the CC-BY-NC-ND 4.0 Licence.

This version is made available in accordance with publisher policies. Please cite only the published version using the reference above. This is the citation assigned by the publisher at the time of issuing the AAM/APV. Please check the publisher's website for any updates. 


\section{Accepted Manuscript}

Surfactants with aromatic headgroups for optimizing properties of graphene/ natural rubber latex composites (NRL): Surfactants with aromatic amine polar heads

Tretya Ardyani, Azmi Mohamed, Suriani Abu Bakar, Masanobu Sagisaka, Yasushi Umetsu, Mohamad Hafiz Mamat, Mohd Khairul Ahmad, H.P.S. Abdul Khalil, Stephen King, Sarah E. Rogers, Julian Eastoe

PII:

S0021-9797(19)30292-9

DOI: $\quad$ https://doi.org/10.1016/j.jcis.2019.03.012

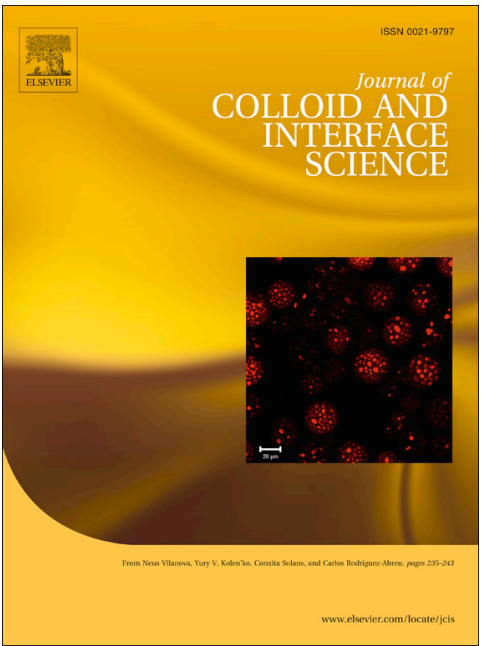

Reference:

YJCIS 24733

To appear in: $\quad$ Journal of Colloid and Interface Science

Received Date: $\quad 29$ January 2019

Revised Date: $\quad 4$ March 2019

Accepted Date: $\quad 5$ March 2019

Please cite this article as: T. Ardyani, A. Mohamed, S. Abu Bakar, M. Sagisaka, Y. Umetsu, M. Hafiz Mamat, M. Khairul Ahmad, H.P.S. Abdul Khalil, S. King, S.E. Rogers, J. Eastoe, Surfactants with aromatic headgroups for optimizing properties of graphene/natural rubber latex composites (NRL): Surfactants with aromatic amine polar heads, Journal of Colloid and Interface Science (2019), doi: https://doi.org/10.1016/j.jcis.2019.03.012

This is a PDF file of an unedited manuscript that has been accepted for publication. As a service to our customers we are providing this early version of the manuscript. The manuscript will undergo copyediting, typesetting, and review of the resulting proof before it is published in its final form. Please note that during the production process errors may be discovered which could affect the content, and all legal disclaimers that apply to the journal pertain. 


\section{Graphical Abstract}

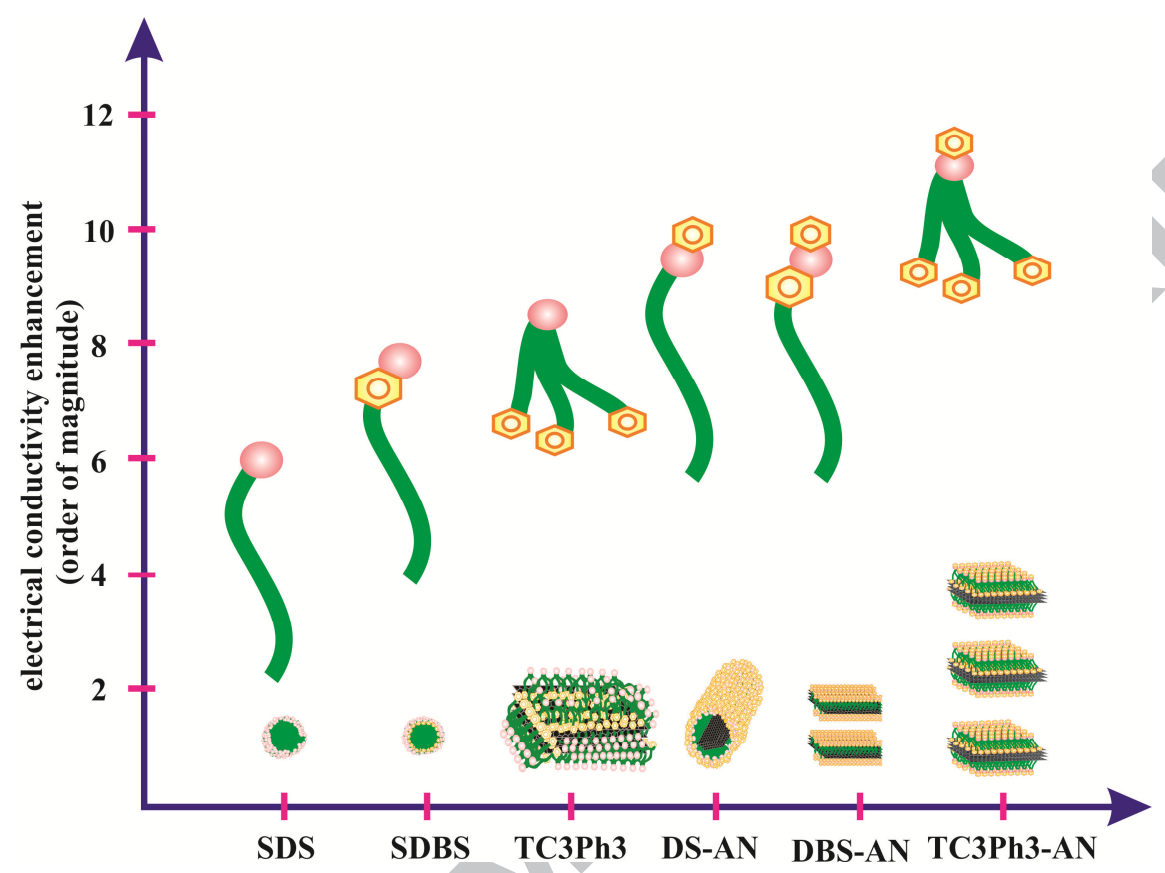


Surfactants with aromatic headgroups for optimizing properties of graphene/natural rubber latex composites (NRL): Surfactants with aromatic amine polar heads

Tretya Ardyani ${ }^{1}$, Azmi Mohamed ${ }^{1,2 *}$, Suriani Abu Bakar ${ }^{2}$, Masanobu Sagisaka ${ }^{3}$, Yasushi Umetsu ${ }^{3}$ Mohamad Hafiz Mamat ${ }^{4}$, Mohd Khairul Ahmad ${ }^{5}$, H.P.S. Abdul Khalil ${ }^{6}$ Stephen King ${ }^{7}$, Sarah E. Rogers ${ }^{7}$, Julian Eastoe ${ }^{8}$

${ }^{1}$ Department of Chemistry, ${ }^{2}$ Nanotechnology Research Centre, Faculty of Science and Mathematics, Universiti Pendidikan Sultan Idris, 35900 Tanjong Malim, Perak, Malaysia

${ }^{3}$ Department of Frontier Materials Chemistry, Graduate School of Science and Technology, Hirosaki University, Bunkyo-cho 3, Hirosaki, Aomori 036-8561, Japan

${ }^{4}$ NANO-SciTech Centre (NST), Institute of Science (IOS), Universiti Teknologi MARA (UiTM), 40450 Shah Alam, Selangor, Malaysia

${ }^{5}$ Microelectronic and Nanotechnology - Shamsuddin Research Centre (MiNT-SRC), Faculty of Electrical and Electronic Engineering, Universiti Tun Hussein Onn Malaysia, 86400 Parit Raja, Batu Pahat, Johor, Malaysia

${ }^{6}$ School of Industrial Technology, Universiti Sains Malaysia, 11700 Gelugor, Penang, Malaysia

${ }^{7}$ Rutherford Appleton Laboratory, ISIS Spallation Source, Chilton, Oxfordshire, OX110QT, United Kingdom

${ }^{8}$ School of Chemistry, University of Bristol, Cantock's Close, Bristol, BS8 1TS, United Kingdom

*Corresponding author. Tel.: +601548797582; fax: +601548797296 


\begin{abstract}
Hypothesis: The compatibility of surfactants and graphene surfaces can be improved by increasing the number of aromatic groups in the surfactants. Including aniline in the structure may improve the compatibility between surfactant and graphene further still. Surfactants can be modified by incorporating aromatic groups in the hydrophobic chains or hydrophilic headgroups. Therefore, it is of interest to investigate the effects of employing anilinium based surfactants to disperse graphene nanoplatelets (GNPs) in natural rubber latex (NRL) for the fabrication of electrically conductive nanocomposites.

Experiments: New graphene-philic surfactants carrying aromatic moieties in the hydrophilic headgroups and hydrophobic tails were synthesized by swapping the traditional sodium counterion with anilinium. ${ }^{1} \mathrm{H}$ NMR spectroscopy was used to characterize the surfactants. These custom-made surfactants were used to assist the dispersion of GNPs in natural rubber latex matrices for the preparation of conductive nanocomposites. The properties of nanocomposites with the new anilinium surfactants were compared with commercial sodium surfactant sodium dodecylsulfate (SDS), sodium dodecylbenzenesulfonate (SDBS), and the previously synthesized aromatic tri-chain sodium surfactant TC3Ph3 (sodium 1,5-dioxo-1,5-bis(3-phenylpropoxy)-3((3phenylpropoxy)carbonyl) pentane-2-sulfonate). Structural properties of the nanocomposites were studied using Raman spectroscopy, field emission scanning electron microscopy (FESEM), and high-resolution transmission electron microscopy (HRTEM). Electrical conductivity measurements and Zeta potential measurements were used to assess the relationships between total number of aromatic groups in the surfactant molecular structure and nanocomposite properties. The self-assembly
\end{abstract}


structure of surfactants in aqueous systems and GNP dispersions was assessed using small-angle neutron scattering (SANS).

Findings: Among these different surfactants, the anilinium version of TC3Ph3 namely TC3Ph3-AN (anilinium 1,5-dioxo-1,5-bis(3-phenylpropoxy)-3((3phenylpropoxy)carbonyl) pentane-2-sulfonate) was shown to be highly efficient for dispersing GNPs in the NRL matrices, increasing electrical conductivity eleven orders of magnitude higher than the neat rubber latex. Comparisons between the sodium and anilinium surfactants show significant differences in the final properties of the nanocomposites. In general, the strategy of increasing the number of surfactant-borne aromatic groups by incorporating anilinium ions in surfactant headgroups appears to be effective.

Keywords: Graphene nanoplatelets (GNPs), Natural rubber latex (NRL), Anionic anilinium surfactants, Dispersion stability, Small-angle neutron scattering (SANS) 


\section{Introduction}

Research related to surfactants lies at the interface of several research disciplines. As a result, the growing interest in new materials often requires consideration of tailored surfactants to improve compatibility and stability of dispersions. The possibilities for structural variations and the implications for physicochemical properties, micellar behavior and potential applications are important in this area. Changes in surfactant molecular structure may include variation of the relative size of hydrophobic parts, hydrophilic headgroup type, single or multiple headgroups, and many other possibilities. The results of these studies (in various colloidal systems e.g. oil-in-water emulsions, carbon nanotube dispersions etc.) are complex, and more often than not, no clear pattern emerges $[1,2]$.

It is a well-known concept in colloid science that a balance between hydrophilic and hydrophobic moieties strongly affects surfactant behavior [3, 4]. The traditional molecular packing (CPP) approach proposed by Israelachvili emphasized the role of each part of the surfactant (volume $\left(v_{o}\right)$ and length $\left(l_{o}\right)$ of surfactant tail and headgroup area $\left(a_{o}\right)$ ), and there are well-established correlations between CPP and micellar structure [5]. Previously, it has been shown that for a constant headgroup structure, interfacial activity, self-assembled structure, and stabilization of graphene dispersions can be dramatically influenced by structural modifications of surfactant hydrophobic groups [6]. Although the employed surfactants differ in total carbon number, trends in electrical conductivity enhancement and zeta potential were found to correlate with the number of aromatic rings and surfactant chains. The observed exceptional behavior of the tri-chain surfactant TC3Ph3 (sodium 1,5-dioxo-1,5-bis(3phenylpropoxy)-3-((3phenylpropoxy)carbonyl) pentane-2-sulfonate) was explained in terms of a suitable "disk-like" geometry for wrapping graphene nanoplatelets (GNPs) 
sheets, resulting in stable dispersions in natural rubber latex (NRL) matrices. The measured values of zeta potential were interpreted in terms of a repulsive stabilizing barrier between adjacent graphene sheets.

Nevertheless, there is a lack of literature related to changes in the surfactant headgroup structure, presumably due to the lack of suitable compounds. It has been recognized that subtle changes of headgroup structure affect the ability of surfactants to stabilize microemulsions, either water-in-oil or water-in- $\mathrm{CO}_{2}$ [7-9]. Briefly, addition of merely a single $-\mathrm{CH}_{2}$ spacer in the surfactant headgroup increases the hydrophobicity and slightly increases the efficiency of the surfactant, enhancing notably microemulsion stability (stable at lower experimental condition) [7-9]. In most cases, though, modifying the hydrophilic segment has much less effect on stability, as compared to for the hydrophobic segment. Another strategy, changing surfactant counterions with aromatic ions generally leads to an increase in hydrophobicity (lower aqueous phase $\mathrm{cmc}$ ), which can be advantageous for enhancing the affinity with graphene surfaces (considering graphene is notoriously hydrophobic) [10-13]. The presence of $\pi$-electron systems in surfactant headgroups may also encourage $\pi-\pi$ interactions with graphene. Although research has highlighted the important role of $\pi-\pi$ interactions for graphene-active surfactants [14-17], until recently, none of the studies thus far have examined the effects of systematic variations in the hydrophilic segments.

Thus, it is becoming evident that understanding the effect of subtle structural variations in surfactant compatibility with graphene is far from complete. To further explore the effect of surfactant molecular structure, and advance a previous study, modifications in surfactant headgroup structure are reported here. An aromatic amine (aniline) moiety has been incorporated into the surfactant hydrophilic segments, 
which are hereafter referred as the anilinium surfactants. The anilinium analogues of normal sodium surfactants (SDS, SDBS, and TC3Ph3); DS-AN, DBS-AN, and TC3Ph3-AN, have been developed and their performance in systems comprising of GNPs and NRLs was investigated.

The chemical structures of the new anilinium surfactants are shown in Table 1, and for comparison the normal sodium surfactants are also shown. To make further comparisons with related aromatic surfactants, SDBS and TC3Ph3 are also included since these are known to promote $\pi-\pi$ interactions. This approach will provide new insight on how hydrophilic headgroup aromatization affects surfactant performance in the GNP/NRL composites as well as the stabilization mechanisms and aggregate microstructures.

\section{Materials and methods}

\subsection{Materials}

The matrix polymer, NRL was supplied by the Malaysian Institute of Nuclear Technology Research, with the total solid content (TSC) and dry rubber content (DRC) were 54\% and 56\%, respectively. Methods to determine the TSC and DRC can be found elsewhere [18]. GNP powder (UG Pro 880, average thickness $0.98-3.54$ nm) was obtained from UGENT Tech Pte Ltd and dried in an oven for $6 \mathrm{~h}$ at $70^{\circ} \mathrm{C}$ prior to use. SDS (99\%, Systerm) and SDBS (technical grade, Sigma Aldrich) were used as received. The surfactants $\mathrm{TC} 3 \mathrm{Ph} 3$ were custom-made and synthesized as detailed previously [19]. The anilinium surfactants however were synthesized according to the previous method by Vega-Rios et al. [20] with certain modifications (see below). The synthesized surfactants were characterized by ${ }^{1} \mathrm{H}$ NMR Spectroscopy detailed in Supplementary material. 


\subsection{Surfactant synthesis}

Anilinium surfactants were prepared by first reacting aniline $\left(\begin{array}{ll}1.0 & \text { eq. }\end{array}\right)$ and hydrochloric acid (37\%) (1.3 eq.) under vigorous stirring to obtain brown colored intermediate anilinium hydrochloride salts. Water was then added up to dissolution of the salt. A known amount of surfactant $(1: 1$ molar ratio to aniline) solution was then added to the resulting anilinium hydrochloride solution while stirring. A white precipitate was formed as a result of exchange between sodium and anilinium ions. Next, the mixture was heated at $50^{\circ} \mathrm{C}$ under stirring up until saturation, and then allowed to cool at room temperature. The mixture was then refrigerated overnight, to separate solid anilinium surfactant, which was then dried at $70^{\circ} \mathrm{C}$. The anilinium surfactants were brown liquids at temperature $\pm 50^{\circ} \mathrm{C}$ and above, but solids at room temperature.

\subsection{Nanocomposite preparation}

The GNP dispersions were prepared using surfactants, and a Branson 5510 sonicator, with $135 \mathrm{~W}$ of $42 \mathrm{kHz}$ ultrasound. Surfactant concentrations were varied from 0 to $0.024 \mathrm{M}$. For comparable studies, the filler loading was fixed at $2 \mathrm{wt} \%$, relative to the TSC of the NRL. A known amount of GNP was initially dispersed in a $10 \mathrm{~mL}$ surfactant solution and stirred for $1 \mathrm{~h}$. The resulting dispersions were then subjected to sonication for $2 \mathrm{~h}$. Next NRL was added to the graphene-stabilized surfactant dispersions and stirred for $1 \mathrm{~h}$. The mixtures were then sonicated and cast into a mould. Nanocomposites were obtained after drying in an oven at $70^{\circ} \mathrm{C}$ overnight. 


\subsection{Electrical conductivity measurements}

Electrical conductivity of the nanocomposites was determined using a standard fourpoint probe method. All samples were cut into $15 \mathrm{~mm}$ x $15 \mathrm{~mm}$ and measured for the surface (in-plane) direction. For each sample, conductivity data represent the averages of triplicate measurements. All conductivity measurements were performed at room temperature $\left(25^{\circ} \mathrm{C}\right)$ with a programmable Keithley 2636A electrometer.

\subsection{Morphology characterization}

The dispersion of GNP flakes in the NRL matrix was studied using Raman spectroscopy, field emission scanning electron microscopy (FESEM) and highresolution transmission electron microscopy (HRTEM). For FESEM (Hitachi SU8020) observation, the nanocomposites were coated with platinum (Pt) prior to imaging to avoid charging. To visualize the embedded microstructure of nanocomposites using HRTEM (JEOL 2100F), the samples were cryo-sectioned with a diamond knife to give nominal thickness of $\sim 80 \mathrm{~nm}$. Raman spectroscopy was used to evaluate the graphitic structure of GNPs. The Raman spectra were collected using a Renishaw InVia micro Raman system spectrophotometer with a 514 nm argon-ion laser source. Five regions were measured for each nanocomposite.

\subsection{Zeta potential measurements}

Zeta potential measurements were performed by ELSZ-1000 Zeta-potential and Particle size Analyzer (Photal OTSUKA ELECTRONICS) using the Smoluchowski equation and 1 peak Lorentz fitting. Measurements were carried out with a flow cell at sampling time $400 \mu \mathrm{s}$, cumulative number 7 , measuring angle $15^{\circ}$, temperature 25 ${ }^{\circ} \mathrm{C}$, pin hole size $50 \mu \mathrm{m}$, cell constant $70.000 \mathrm{~cm}^{-1}$. Properties of aqueous mixtures 
(refractive index 1.3328 , viscosity $0.8878 \mathrm{cP}$, and permittivity $78.3 \mathrm{Fm}^{-1}$ ) were used for calculation of zeta potential. Zeta potential values were finally obtained as average values of 10 runs for each sample.

\subsection{Small-angle neutron scattering (SANS)}

Small-Angle Neutron Scattering (SANS) studies were carried out on the time-of-flight LOQ instrument at ISIS, UK. The accessible Q range was $0.007-0.23 \AA^{-1}$, arising from incident neutron wavelengths of $\lambda=2.2-10 \AA$. Absolute intensities for $I(Q)$ $\left(\mathrm{cm}^{-1}\right)$ were determined to within $5 \%$ by measuring the scattering from a partially deuterated polymer standard. Neutrons are scattered by short-range interactions with sample nuclei, the 'scattering power' of different components being defined by a scattering-length density (SLD), $\rho\left(\mathrm{cm}^{-2}\right)$. The samples were prepared in $2 \mathrm{~mm}$ pathlength quartz cells and held in a thermostatted automatic sample changer at $25^{\circ} \mathrm{C}$. Data have been fitted using the SASView interactive fitting program, fixing scattering length density differences as calculated and fitting for micellar volume fraction and appropriate structural parameters as required by the different scattering laws.

\section{Results and discussion}

\subsection{Electrical conductivity measurements}

Added surfactants perform important functions for enhancing the mechanical, thermal, and electrical properties of the composites. Electrical conductivity measurements have been used help assess the performance of different surfactants in GNP and NRL composites. The results are shown as a function of log electrical conductivity versus surfactant concentration (Fig. 1). It can be seen that the effect of swapping sodium counterions for anilinium is quite dramatic; the electrical properties 
of the resulting nanocomposites are notably improved. Table 2 summarizes the comparison of conductivity values when using the anilinium surfactants. Other related data for nanocomposite electrical conductivities are given in Table S1 (Supplementary material).

Generally, the anilinium version brings about three orders of magnitude enhancements to the electrical conductivity at the same surfactant concentration. For example, with SDS at $0.024 \mathrm{M}$, the optimum nanocomposite electrical conductivity was $1.59 \times 10^{-8} \mathrm{~S} \mathrm{~cm}^{-1}$. However, the anilinium analogue (DS-AN) is able to reach $3.45 \times 10^{-6} \mathrm{~S} \mathrm{~cm}^{-1}$ at the same concentration. Optimum electrical conductivity was achieved at a surfactant concentration of $0.016 \mathrm{M}$, giving $1.50 \times 10^{-4} \mathrm{~S} \mathrm{~cm}^{-1}$; even higher than for the tri-chain surfactant TC3Ph3 (Table 2; Table S1). The most remarkable enhancement here was found with $\mathrm{TC} 3 \mathrm{Ph} 3-\mathrm{AN}$ at $0.008 \mathrm{M}$, elevating the non-conductive NRL $\left(1.51 \times 10^{-14} \mathrm{~S} \mathrm{~cm}^{-1}\right)$ by nearly twelve orders of magnitude to $1.08 \times 10^{-2} \mathrm{~S} \mathrm{~cm}^{-1}$ ). It is interesting to note that TC3Ph3-AN needed only half the $\mathrm{TC} 3 \mathrm{Ph} 3$ concentration to achieve optimum nanocomposite electrical conductivity (TC3Ph3 at $0.016 \mathrm{M}$; TC3Ph3-AN at $0008 \mathrm{M}$ ). The optimum electrical conductivity follows the order of TC3Ph3-AN > DBS-AN > DS-AN, although there is only a slight difference between DS-AN and DBS-AN.

The electrical properties of these composites compare well with the top ranking values reported in the literature for graphene-polymer nanocomposites [2123]. The most impressive enhancement seen here is almost the same as was achieved at ten times higher surfactant concentrations [22] and nanofiller content [24]. Returning to Table 2, the changes in electrical conductivity are broadly consistent with increasing surfactant concentration $[15,25]$. However, that is not always the case, for example with TC3Ph3-AN. The same kind of behavior was also experienced 
with $\mathrm{TC} 3 \mathrm{Ph} 3$, again illustrating that surfactants may cease to "perform" at a certain limit $[25,26]$. It is clear that aromatization of the headgroups enhances graphenecompatibility compared with the normal sodium surfactants. The relationships between these interesting phenomena and the surfactant electrical double layers generated by the surfactants will be presented in the following sections.

\subsection{Morphologies of dispersions}

To gain more information on the organization of GNPs in the polymer matrices, FESEM microscopy has been used which can provide contrast imaging between polymer host and nanofiller. FESEM images show individual graphene sheets represented by the bright flakes, which are well dispersed throughout the NRL matrices (Fig. 2). Attempts to disperse the GNPs using sodium surfactants (at 0.016 M) followed clear improvements on increasing the number of aromatic rings in the hydrophobic segments [6]. GNPs were observed as numerous bright flakes against the dark background NRL matrices [27, 28]. Compared to the non-aromatic SDS better quality dispersions were achieved with aromatic single chain SDBS, which further improved using TC3Ph3 (Fig. S4; Supplementary material), giving less agglomerates and better dispersed structures over the sample surface area [6].

As can be seen in the SEM images of Fig. $2(\mathrm{a}-\mathrm{c})$, at constant surfactant concentration $(0.016 \mathrm{M})$ the composites stabilized by anilinium surfactants appear to be almost entirely filled with GNPs. The edges and multiple layers of GNP flakes become more evident when observed at higher magnification ( $\left.a^{\prime}-c^{\prime}\right)$. These observations suggest that the GNPs are present individually, with only minimal stacking or agglomeration. This is distinctively different then when the dispersion is stabilized by sodium surfactants. With the same magnification range, even the best 
surfactant TC3Ph3 was not able to achieve dominantly-covered surfaces (Fig. 2. d and d'). This indicates that the GNP sheets are more uniformly distributed and intimately mixed within the NRLs when anilinium surfactants are used, and is presumably the origin of the enhancements in electrical properties discussed in the previous section.

To further examine the microdispersion state of GNPs in NRLs HRTEM was employed. Fig. 3. $(a-c)$ shows TEM micrographs of ultrathin sections of GNP/NRL/TC3Ph3-AN composites. Over the imaging area, a few randomly oriented GNP platelets are visible, the dark needle-like particles, indicate multiple GNP layers [29-31]. A higher resolution TEM investigation of the free-hanging sheets as shown in Fig. 3 (c) provides direct visualization of the number of GNP layers.

By comparison, TC3Ph3-AN promotes a more uniform dispersion, with more GNPs embedded in the NRL matrix, as compared to TC3Ph3 (Fig. S5; Supplementary material). It is clear that GNPs are well-mixed with the NRL matrices, and this may be ascribed to strong interactions between the functional groups on NRL particles and the charged GNPs wrapped by surfactants. Therefore, it can be deduced that good dispersion of GNPs inside these NRL matrices is related to improved electrical properties of these nanocomposites.

The graphitic networks in the nanocomposites were further characterized by Raman spectroscopy. Two peaks that are commonly ascribed to graphene, the $D$ $\left(1350 \mathrm{~cm}^{-1}\right)$ and $G$-bands $\left(1580 \mathrm{~cm}^{-1}\right)$, are seen in Fig. 4. As such, the presence of defect domains in GNPs can be assessed by calculating the ratio of defect disorder $(D$ band) and graphitic network ( $G$-band) intensity, namely $I_{D} / I_{G}$ ratio [32].

As can be seen, the Raman spectra of nanocomposites are dominated by the $s p^{2}$ sites, as those found in GNPs where the $G$-peak is more pronounced than the $D$ peak. The $D$-peak appeared almost at the same wavenumber as that of the pure GNPs 
except for composites containing TC3Ph3 surfactant (see Fig. S6), which shifted to higher wavenumber (1353 to $1358 \mathrm{~cm}^{-1}$ ). Interestingly, when comparing the $G$-peaks of the nanocomposites and GNPs, the nanocomposites and GNPs exhibit relatively strong $G$-bands at around $1580-1581 \mathrm{~cm}^{-1}$ but not for TC3Ph3-AN. The G-peak of a sample containing TC3Ph3-AN appeared at higher wavenumber $\left(1589 \mathrm{~cm}^{-1}\right)$ compared to the other samples, which may be attributed to the surfactant wrapping the GNP particles [32-34].

Analysis of the $I_{D} / I_{G}$ ratio revealed slightly decreased $I_{D} / I_{G}$ values of GNPs in the nanocomposites compared to the pristine GNPs. This is assumed to be due to the surfactant physically wrapping GNP sheets, but not altering the $s p^{2}$ GNP network [19, 35]. Therefore, it can be concluded that the graphitic networks are mainly intact and surfactant treatments used here do not covalently functionalize or perturb the nanocomposite $\pi$-systems. The surfactants are able to preserve graphitic networks uniformly dispersed and overcome agglomeration, resulting in high electrical conductivity enhancements.

3.3 Relationship between number of aromatic groups in surfactants, dispersion stability and electrical conductivity enhancement - a zeta potential study

The zeta (ら)-potentials of graphene dispersions with anilinium surfactant in this study are well beyond the accepted value for colloidal stability $( \pm 30 \mathrm{mV}$, see Table 3$)$, indicating that reaggregation should be minimized. Readers may refer to Table S2 (Supplementary material) for the zeta-potential data of normal sodium surfactants. It is clear that the electrostatic stabilizing barrier provided by surfactant is strongly dependent on surfactant structure [36]. 
Compared to the parent SDBS, the barrier increased to $-63 \mathrm{mV}$ for the anilinium analogue. The $\zeta$-potential of DS-AN surfactant however is quite similar to SDS, being slightly shifted to $-45 \mathrm{mV}$. On the other hand, the greatest charge stability was achieved with TC3Ph3-AN, reaching up to $-99 \mathrm{mV}$. Although, considering experimental error, this value is just slightly beyond the optimum value reached with the TC3Ph3 surfactant. Nevertheless, this impressive zeta potential of $-99 \mathrm{mV}$, makes it the most negative zeta potential value observed for graphene as well as CNTs studies to date $[14,15,37,38]$.

Using pyrene derivatives, Parviz and co-workers studied the variation of remaining graphene fraction after centrifugation as well as the $\zeta$-potential over wide $\mathrm{pH}$ range $(2-12)$. Among six compounds, only few (mostly sulfonyl-bearing compounds) qualify as colloidally stable, being slightly negative or positive than the "stability benchmark" ( $\pm 30 \mathrm{mV})$ [15]. Other work from the same group employed triphenylene derivatives for the fabrication of conductive composites from poly(vinyl) alcohol. A potential of $-37 \mathrm{mV}$ was cited as one of the factors affecting improved electrical conductivity [14]. Later, Zhang et al. designed a conjugated $\pi$-rich compound, namely a naphthalene surfactant, for dispersion to give absolute potential barriers of $|35-50| \mathrm{mV}$ [16]. It is evident that the custom-made surfactants used here clearly outperform the already existing aromatic compounds used in previous literature. Considering the price of starting materials and the performance of the resulting composites, the surfactants used here are more economical for larger scale synthesis than the aforementioned compounds (e.g. the precursor of naphthalene surfactant cost about USD 80/5g, whereas TC3Ph3 precursor cost about USD 0.60/5g - based on the current rates from commercial suppliers). 
Coming back to the nanocomposite electrical properties, there is a trend toward greater electrical conductivity as the total number of surfactant aromatic rings is increased; this suggests that dispersion stability (zeta potential) increases with more $\pi-\pi$ interactions. A relationship between electrical conductivity enhancement, zeta potential value, and total number of aromatic rings is shown in Fig. 5. It is clear that highly charged GNPs help to achieve stable dispersions in the NRL matrices and enhanced nanocomposite properties.

3.4 Effect of headgroup modification on structure of surfactant aggregates by SANS

The morphology of surfactants aggregates and micelles is a result of delicate balance of two opposing forces [39-41]. Tail-tail interactions provide promote aggregation, whereas repulsion between surfactants limits the eventual micelle size [42, 43]. As a result, the characteristics of these aggregates can be easily controlled by changes in surfactant molecular structure or solution conditions such as temperature, concentration and ionic strength [44]. To gain a better understanding of the influence of aromatic rings in headgroups on micellar structure SANS profiles surfactants were examined at a fixed concentration. The SANS profiles for anilinium surfactant solutions are displayed in Fig. 6 (a), whereas the GNP dispersions are in Fig. 6 (b). All measurements were carried out at a concentration of $0.03 \mathrm{M}$, being above the $\mathrm{cmc}$ all surfactants. The fitted micellar dimensions of each surfactant can be found in Table 4. The SANS data for sodium surfactants are given in Supplementary material (Fig. S7 and Table S3).

For all the single chain sodium surfactants (Fig. S7 (a)), the scattering is consistent with charged spherical micelles $[45,46]$. The scattering from the tri-chain 
TC3Ph3 surfactant could be interpreted as charged ellipsoidal micelles, and a form factor $P(Q)$ with principal and secondary axes $R_{a}$ and $R_{b}$. The interparticle structure factors $S(Q)$ were modeled for interacting charged micelles by the Hayter-Penfold method [46]. On moving to the anilinium version, with DS-AN surfactant there is a sphere-to-rodlike transition (Fig. 6 a). For this sample $I(Q)$ scales approximately with $Q^{-1}$ which is characteristic for 1-D rodlike micelles (Fig. S7 a). The micelle radius of SDS was initially $22.0 \AA$, shrinking to $14.0 \AA$ with DS-AN. However, the micelles elongate and grow uniaxially to give a rod length around $168.0 \AA$. Previous work observed similar micellar growth behavior when aniline hydrochloride was introduced to SDS micelles [47-50]. The presence of aromatic rings was postulated to screen the headgroup electrostatic repulsions, which in turn, decreases the effective area occupied by surfactant headgroups [47]. This was corroborated by SANS analyses which revealed a decrease in headgroup area at higher aniline hydrochloride concentration.

The transition was also discussed in terms of the molecular packing parameter CPP). A lower headgroup area increases CPP for the surfactant and induces a transition from spherical to rodlike or lamellar micelles $[5,39,51]$. Rod formation in cationic surfactants is also often encountered when aromatic counterions are present, although it does depend on the type of aromatic ring [10, 52, 53].

The scattering data of DBS-AN and TC3Ph3-AN shown in Fig. 6 (a) are indicative of lamellar aggregates, where DBS-AN forms regular bilayer micelles and TC3Ph3-AN forms stacks of eleven or so bilayer micelles. The layer thicknesses respectively are 45.0 and $108.0 \AA$. The fitted micellar dimensions are $L$, bilayer thickness $M$, number of bilayers and $D$, interlayer distance. Through TEM observations and ${ }^{1} \mathrm{H}$ NMR spectroscopy, Mohanty and Dey suggested that the 
formation of bilayer vesicles is encouraged by $\pi-\pi$ stacking between phenyl bearing headgroups coupled with intermolecular hydrogen bonding between neighboring amine groups [12]. The formation of bilayers has also been reported for single tail dodecyl surfactants on addition of aromatic ions (salicylic and cinnamic acid) $[11,54$, $55]$.

When GNP is added to the micelles, there are no obvious overall effects on micelle shape for SDS and SDBS (Table S3). On the other hand, a "disk-like" morphology is seen when GMPs are added to $\mathrm{TC} 3 \mathrm{Ph} 3$ micelles. It was previously suggested that this disk-like aggregate is responsible for the formation of stable GNP dispersions in water [6].

SANS data from GNP dispersions with DS-AN is still similar to that for the parent surfactant solution, consistent with cylindrical micelles (see Table 4). It might be that the GNPs are dispersed inside the cylindrical cores, hence the dimension was not greatly affected. Another more likely scenario is that the SANS is dominated by surfactant aggregates instead of surfactant-GNP aggregates. The surfactant might coexist as micelles and adsorbed on GNP surfaces [56], hence the SANS is indicating mainly cylindrical micelles. This might be true considering that FESEM also revealed the more irregular size of the pristine GNP flakes (Fig. 2. a).

Moving now to other chemical structures, both DBS-AN and TC3Ph3-AN give scattering consistent with a lamellar stack model. DBS-AN transforms to double stacks of bilayers (two layers in a stack $M=2$ ). For TC3Ph3-AN, analysis suggests no shape transition; maintaining the multilamellar shape. Surprisingly, however, the number of bilayers, $M$, dramatically increases from 11 to 37 . Furthermore, the bilayer separation, $D$, increased substantially by about $20 \AA$. The bilayer thickness increased approximately in line with the length of a dodecyl chain $(16.7 \AA)[47,57]$. Hence, this 
shows evidence for GNP dispersion, as detected by the increasing number of layers per stack. These results also indicate that inclusion of aromatic rings in the surfactant headgroups significantly affects the micellar properties.

3.5 Mechanism of anilinium surfactant self-organization in aqueous solutions and graphene surfaces

It is fair to conclude that the anilinium tri-chain surfactant $\mathrm{TC} 3 \mathrm{Ph} 3-\mathrm{AN}$ provides significant improvement in GNP dispersion and stability compared to the normal sodium surfactant, TC3Ph3. Scattering experiments showed two distinct micellar behaviors, and in the presence of GNPs. TC3Ph3 was shown to undergo an ellipsoidto-stacked disk transformation with added GNPs, whereas the cousin TC3Ph3-AN maintained the lamellar stack aggregate structure even after GNP addition. On the basis of SANS analysis, a schematic of TC3Ph3-AN self-assembly is depicted in Fig. 7, which will be discussed below.

An account of aggregation that is consistent with the SANS data is needed. TC3Ph3-AN formed stacks of bilayers because of the headgroup anilinium moieties due to intermolecular hydrogen bonding and $\pi-\pi$ stacking. Here, as can be seen in Fig. 7, the bilayer is proposed to be composed of two monolayers and may extend indefinitely [44]. For the case of multilamellar stacks, there is a certain number of bilayers separated by water. At this point, the aniline ions may reside in the region between hydrophobic cores and the Stern layer [13], whereas, the sulfate groups interact with water or NRL functional groups [58, 59].

When GNPs are added they will reside in the hydrophobic bilayer cores to interact through $\pi-\pi$ interactions with the aromatic-bearing tails. The presence of aniline ions in the outer aqueous layer is speculated to favor interactions with GNP 
surfaces through a $\pi$-conjugated network. As a result, the overall interaction of surfactant with GNP is strengthened (and this follows increasing number of surfactant aromatic groups), providing the stability to bilayer structures [13, 17]. It is this "sandwich-like" structure of GNP/TC3Ph3-AN micelles that can be credited for to the improved dispersion. The hydrophilic headgroups meanwhile are facing away from the graphene surfaces and interact with the shell layer latex particles $[59,60]$.

Now one remaining question is "why do the sodium surfactants undergo shape transitions, whereas the anilinium analogues do not?" It is known that changes in solution conditions (temperature, additives, $\mathrm{pH}$ and so on) may induce micellar shape changes $[44,61]$. Halle and others have suggested that micellar transitions due to electrostatic interactions or with additives may occur easily since they require only small thermodynamic (enthalpy and entropic) penalties [61, 62]. Spherical or ellipsoidal micelles are often assumed to grow length-wise to form cylindrical micelles [61], or shape transitions may also may occur owing to the splitting and rearrangement of spherical micelles into two hemispheres [63]. Hence, it is plausible that addition of GNP may facilitate the rearrangement of $\mathrm{TC} 3 \mathrm{Ph} 3$ into ellipsoidal structures to adopt to the shape of GNP plates.

The case is different for TC3Ph3-AN and DBS-AN. Even without GNPs, the surfactants are already associated into bilayers. Bilayers may close in to form vesicles or liposomes, or extended in three dimensions to form sponge-like phases [44, 64]. This is because bilayer structures possess a remarkable degree of internal stability [64]. For example, after formation of vesicles they can be stable for few days or even months before evolving into more complicated structures. For this reason, when GNPs are added, the bilayer structure will not undergo shape changes, but instead, increasing the number of bilayers $(M)$ to accommodate and stabilize the added GNPs. 
The stronger $\pi-\pi$ interactions between the conjugated cores of aniline groups and graphene surfaces are thought to be a major factor governing the improved nanocomposite electrical properties [65]. A density functional theory (DFT) analysis study revealed that between benzene, toluene, aniline and nitrobenzene, benzene has the largest (3.12 $\AA$ ) equilibrium distance toward graphene surfaces [66]. Aniline is among the shortest from the investigated compounds, with a distance of $2.86 \AA$. It was suggested that the presence of these very functional groups will attract the molecules closer to the graphene surfaces. Analysis of adsorption energies also indicated the tendencies of aromatic molecules to physically adsorb onto graphene surfaces, instead of grafting or altering the $\pi$-conjugated network [66]. Thus, the presence of aniline, even though in the surfactant headgroup, may possibly bring the surfactant molecules closer to the graphene surface to promote enhanced $\pi-\pi$ interactions. Taking all the factors together, it can be suggested that incorporation of heteroaromatic groups is a suitable strategy for developing enhanced graphenecompatible surfactants.

\section{Conclusions}

Based on previous studies [6, 17,19], the effect of varying surfactant headgroup chemistry with ionic surfactants was investigated. These new headgroup structures had profound effects on electrical conductivity enhancement and aggregation behavior of the GNP-NRL nanocomposites. This reveals the remarkable versatility of anilinium surfactants for applications with graphene. The general observation of the surfactant structure-performance relationship for these amphiphiles is that addition of aromatic moieties to the headgroups have greater effects than if added to the tails instead [6]. The presence of aniline in headgroups is speculated to improve 
interactions between surfactant molecules and graphene surfaces [66]. The nature of the aromatic substituents was found to govern the size and shape of micelles, where the most surfactants for GNP dispersion stabilized lamellar structures. Compared with other aromatic compounds used for graphene dispersions, these newly synthesized anilinium surfactants promise greater dispersion quality with lower loading and cheaper raw materials [14-16, 67]. As such surfactants based on anilinium moieties are very versatile, they can be custom designed with other hydrophobic tails by simple counterion exchange, and they can be employed for a broad range of graphene-based applications, as shown here, or reaction templates for polymerization as demonstrated elsewhere [20].

\section{Acknowledgments}

The work funded under grants from Kurita Water and Environment Foundation (Grant Code: 16P003) and the Fundamental Research Grant Scheme (FRGS; Grant code: 2015-0155-101-02). This project was supported by JSPS [KAKENHI, Grant-inAid for Young Scientists (A), No. 23685034], and Leading Research Organizations (RCUK [through EPSRC EP/I018301/1], ANR [13-G8ME-0003]) under the G8 Research Councils Initiative for Multi-lateral Research Funding-G8-2012. The authors thank the Science and Technology Facilities Council for allocation of beam time, travel and consumables (experiment number RB1710004). This work benefited from the use of the SasView application, originally developed under NSF Award DMR-0520547. SasView also contains code developed with funding from the EU Horizon 2020 programme under the SINE2020 project Grant No 654000. 


\section{References}

1. L. Vaisman, H. D. Wagner, G. Marom, The Role of Surfactants in Dispersion of Carbon Nanotubes, Adv. Colloid Interface Sci 128-130 (2006) 37-46, https://doi.org/10.1016/j.cis.2006.11.007

2. J. Eastoe, S. Gold, Self-assembly in Green Solvents, Phys. Chem. Chem. Phys 7 (2005) 1352-1362, https://doi.org/10.1039/B418985J

3. J. Goodwin, Colloids and Interfaces with Surfactants and Polymers, $2^{\text {nd }}$ ed: John Wiley \& Sons: West Sussex, 2009.

4. M. J. Rosen, Surfactant and Interfacial Phenomena, $3^{\text {rd }}$ ed:John Wiley $\&$ Sons: New Jersey, 2004.

5. J. N. Israelachvili, D.J. Mitchell, and B.W. Ninham, Theory of Self-Assembly of Hydrocarbon Amphiphiles into Micelles and Bilayers, J. Chem. Soc., Faraday Trans. 272 (1976) 1525-1568, https://doi.org/10.1039/F29767201525

6. A. Mohamed, T. Ardyani, S. Abu Bakar, M. Sagisaka, Y. Umetsu, J. J. Hamon, B. A. Rahim, S. R. Esa, H. P. S. Khalil, M. H. Mamat, S. King, J. Eastoe, Rational Design of Aromatic Surfactants for Graphene/Natural Rubber Latex Nanocomposites with Enhanced Electrical Conductivity, J. Colloid Interface Sci 516 (2018) 34-47, https://doi.org/10.1016/j.jcis.2018.01.041

7. M. Sagisaka, S. Iwama, A. Yoshizawa, A. Mohamed, S. Cummings, S. E. Rogers, R. K. Heenan, J. Eastoe, Super-Efficient Surfactant for Stabilizing Water-in-Carbon Dioxide Microemulsions, Langmuir 27 (2011) 5772-5780, https://doi.org/10.1021/la104990c 
8. M. Sagisaka, S. Iwama, A. Yoshizawa, A. Mohamed, S. Cummings, J. Eastoe, Effective and Efficient Surfactant for $\mathrm{CO}_{2}$ Having Only Short Fluorocarbon Chains, Langmuir 28 (2012) 10988-10996, https://doi.org/10.1021/la301305q

9. S. Nave, J. Eastoe, R. K. Heenan, D. Steytler, I. Grillo, What Is So Special about Aerosol-OT? Part III - Glutaconate versus Sulfosuccinate Headgroups and Oil-Water Interfacial Tensions, Langmuir 18 (2002) 1505-1510, https://doi.org/10.1021/la015564a

10. S. De, V.K. Aswal, S. Ramakrishnan, Phenyl-ring-bearing Cationic Surfactants: Effect of Ring Location on the Micellar Structure, Langmuir 26 (2010) 17882-17889, https://doi.org/10.1021/la1036053

11. R. T. Buwalda, M.C.A. Stuart, J.B.F.N. Engberts, Wormlike Micellar and Vesicular Phases in Aqueous Solutions of Single-Tailed Surfactants with Aromatic Counterions, Langmuir 16 (2000) 6780-6786, https://doi.org/10.1021/la000164t

12. A. Mohanty, J. Dey, Effect of the Headgroup Structure on the Aggregation Behavior and Stability of Self-Assemblies of Sodium N-[4-(nDodecyloxy)benzoyl]-1-aminoacidates in Water, Langmuir 23 (2007) 1033https://doi.org/1040, 10.1021/la0625143

13. G. Singh, G. Singh, T.S. Kang, Micellization Behavior of Surface Active Ionic Liquids Having Aromatic Counterions in Aqueous Media, J. Phys. Chem. B 120 (2016) 1092-1105, https://doi.org/10.1021/acs.jpcb.5b09688

14. S. Das, F. Irin, H. S. Tanvir Ahmed, A. B. Cortinas, A. S. Wajid, D. Parviz, A. F. Jankowski, M. Kato, M. J. Green, Non-Covalent Functionalization of Pristine Few-Layer Graphene Using Triphenylene Derivatives for Conductive 
Poly (Vinyl Alcohol) Composites, Polymer 53 (2012) 2485-2494, https://doi.org/10.1016/j.polymer.2012.03.012

15. D. Parviz, S. Das, H. S. T. Ahmed, F. Irin, S. Bhattacharia, M. J. Green, Dispersions of Non-Covalently Functionalized Graphene with Minimal Stabilizer, ACS Nano 6 (2012) 8857-8867, https://doi.org/ $10.1021 / \mathrm{nn} 302784 \mathrm{~m}$

16. L. Zhang, Z. Zhang, C. He, L. Dai, J. Liu, L. Wang, Rationally Designed Surfactants for Few-Layered Graphene Exfoliation: Ionic Groups Attached to Electron-Deficient $\pi$-Conjugated Unit through Alkyl Spacers, ACS Nano 8 (2014) 6663-6670, https://doi.org/ 10.1021/nn502289w

17. A. Mohamed, T. Ardyani, S. A. Bakar, P. Brown, M. Hollamby, M. Sagisaka, J. Eastoe, Graphene-philic Surfactants for Nanocomposites in Latex Technology, Adv. Colloid Interface Sci 230 (2016) 54-69, https://doi.org/10.1016/j.cis.2016.01.003

18. Pichayakorn, J. Suksaeree, P. Boonme, W. Taweepreda, G. C. Ritthidej, Preparation of Deproteinized Natural Rubber Latex and Properties of Films Formed by Itself and Several Adhesive Polymer Blends, Ind. Eng. Chem. Res. 51 (2012) 13393-13404, https://doi.org/ 10.1021/ie301985y

19. A. Mohamed, A. K. Anas, S. A. Bakar, T. Ardyani, W. M. W. Zin,, S. Ibrahim, M. Sagisaka, P. Brown, J. Eastoe, Enhanced Dispersion of Multiwall Carbon Nanotubes in Natural Rubber Latex Nanocomposites by Surfactants Bearing Phenyl Groups, J. Colloid Interface Sci 455 (2015) 179-187, https://doi.org/10.1016/j.jcis.2015.05.054

20. A. Vega-Rios, F. Y. Rentería-Baltiérrez, C. A. Hernández-Escobar, E. A. Zaragoza-Contreras, A New Route Toward Graphene Nanosheet/Polyaniline 
Composites Using A Reactive Surfactant as Polyaniline Precursor, Synth. Met. 184 $52-60$ https://doi.org/ https://doi.org/10.1016/j.synthmet.2013.09.014

21. Y. V. Syurik, M. G. Ghislandi, E. E. Tkalya, G. Paterson, D. McGrouther, O. A. Ageev, J. Loos, Graphene Network Organisation in Conductive Polymer Composites, Macromol. Chem. Phys, 213 (2012) 1251-1258, https://doi.org/10.1002/macp.201200116

22. E. Tkalya, M. Ghislandi, A. Alekseev, C. Koning, J. Loos, Latex-based Concept for the Preparation of Graphene-based Polymer Nanocomposites, J. Mater. Chem 20 (2010) 3035-3039, https://doi.org/10.1039/B922604D

23. J. R. Potts, D. R. Dreyer, C. W. Bielawski, R. S. Ruoff, Graphene-based Polymer Nanocomposites, Polymer $52 \quad$ (2011) 5-25, https://doi.org/10.1016/j.polymer.2010.11.042

24. K. Kampioti, C. F. Matos, F. Galembeck, C. Jaillet, A. Derré, A. J. G. Zarbin, A. Pénicaud, Highly Conducting, Sustainable, Nanographitic Rubber Composites, ACS Omega 3 (2018) 1367-1373, https://doi.org/10.1021/acsomega.7b01848

25. S. Wang, M. Yi, Z. Shen, The Effect of Surfactants and their Concentration on the Liquid Exfoliation of Graphene, RSC Adv 6 (2016) 56705-56710, https://doi.org/10.1039/C6RA10933K

26. J. N. Coleman, Liquid-Phase Exfoliation of Nanotubes and Graphene, Adv. Funct. $\quad$ Mater. $19 \quad$ (2009) 3680-3695, https://doi.org/10.1002/adfm.200901640

27. A. Das, G. R. Kasaliwal, R. Jurk, R. Boldt, D. Fischer, K. W. Stöckelhuber, G. Heinrich, Rubber Composites Based on Graphene Nanoplatelets, Expanded 
Graphite, Carbon Nanotubes and Their Combination: A Comparative Study, $\begin{array}{lllll}\text { Compos. } & \text { Sci. } & \text { Technol. } & 72 & \text { (2012) }\end{array}$ https://doi.org/10.1016/j.compscitech.2012.09.005

28. L. Yue, G. Pircheraghi, S. A. Monemian, I. Manas-Zloczower, Epoxy Composites with Carbon Nanotubes and Graphene Nanoplatelets-Dispersion and Synergy Effects, Carbon 78 (2014). 268-278, https://doi.org/10.1016/j.carbon.2014.07.003

29. V. Singh, D. Joung, L. Zhai, S. Das, S. I. Khondaker, S. Seal, Graphene Based Materials: Past, Present and Future, Prog. Mater. Sci. 56 (2011) 1178-1271, https://doi.org/10.1016/j.pmatsci.2011.03.003

30. D. G. Papageorgiou, I. A. Kinloch, R. J. Young, Graphene/Elastomer Nanocomposites, $\quad$ Carbon $\quad 95 \quad$ (2015) 460-484, https://doi.org/10.1016/j.carbon.2015.08.055

31. H. Kim, Processing, Morphology and Properties of Graphene Reinforced Polymer Nanocomposites, $\mathrm{PhD}$ Thesis in Chemical Engineering, University of Minnesotta, 2009, p. 177, http://hdl.handle.net/11299/56729

32. A. C. Ferrari, Raman Spectroscopy of Graphene and Graphite: Disorder, Electron-Phonon Coupling, Doping and Nonadiabatic Effects, Solid State Commun. $143 \quad$ (2007), 47-57, https://doi.org/10.1016/j.ssc.2007.03.052

33. K. N. Kudin, B. Ozbas, H. C. Schniepp, R. K. Prud'Homme, I. A. Aksay, R.Carr, Raman Spectra of Graphite Oxide and Functionalized Graphene Sheets, Nano Lett 8 (2008) 36-41, https://doi.org/10.1021/nl071822y

34. A. C. Ferrari, J. C. Meyer, V. Scardaci, C. Casiraghi, M. Lazzeri, F. Mauri, S. Piscanec, D. Jiang, K. S. Novoselov, S. Roth, A. K. Geim, Raman Spectrum of 
Graphene and Graphene Layers, Phys. Rev. Lett 97 (2006) 187401(1-4), https://doi.org/10.1103/PhysRevLett.97.187401

35. A. Mohamed, A. K. Anas, S. A. Bakar, A. A. Aziz, M. Sagisaka, P. Brown, J. Eastoe, A. Kamari, N. Hashim, I. M. Isa, Preparation of Multiwall Carbon Nanotubes (MWCNTs) Stabilised by Highly Branched Hydrocarbon Surfactants and Dispersed in Natural Rubber Latex Nanocomposites, Colloid Polym. Sci 292 (2014) 3013-3023, https://doi.org/10.1007/s00396-014-33541

36. R. J. Hunter, Zeta Potential in Colloid Science: Principles and Applications, $1^{\text {st }}$ ed; Academic Press: London, 1986.

37. B. White, S. Banerjee, S. O'Brien, N. J. Turro, I. P. Herman, Zeta-Potential Measurements of Surfactant-Wrapped Individual Single-Walled Carbon Nanotubes, J. Phys. Chem C 111 (2007) 13684-13690, https://doi.org/ 10.1021/jp070853e

38. Z. Sun, V. Nicolosi, D. Rickard, S. D. Bergin, D. Aherne, J. N. Coleman, Quantitative Evaluation of Surfactant-Stabilized Single-Walled Carbon Nanotubes: Dispersion Quality and Its Correlation With Zeta Potential, J. Phys. Chem. C 112 (2008) 10692-10699, https://doi.org/10.1021/jp8021634

39. R. Nagarajan, Molecular Packing Parameter and Surfactant Self-Assembly: The Neglected Role of the Surfactant Tail, Langmuir 18 (2002) 31-38, https://doi.org/ 10.1021/la010831y

40. C. Tanford, The Hydrophobic Effect and the Organization of Living Matter, Science, 200 (1978) 1012-1018, https://doi.org/ 10.1126/science.653353 
41. D. F. Evans, B.W. Ninham, Molecular Forces in the Self-Organization of Amphiphiles, J. Phys. Chem 90 (1986) 226-234, https://doi.org/ 10.1021/j100274a005

42. C. Tanford, Interfacial Free Energy and the Hydrophobic Effect, Proc. Natl. Acad. Sci. U. S. A., $76 \quad$ (1979) 4175-4176, https://doi.org/10.1073/pnas.76.9.4175

43. C. Tanford, Thermodynamics of Micelle Formation: Prediction of Micelle Size and Size Distribution, Proc. Natl. Acad. Sci. U. S. A., 71 (1974) 18111815, https://doi.org/10.1073/pnas.71.5.1811

44. D. Fennel Evans, H. Wennerstrom, The Colloidal Domain: Where Physics, Chemistry, Biology and Technology Meet: Wiley-VCH Weinheim, New York, 1994.

45. L. A. Feigin, D. I. Svergun, Structure Analysis by Small-Angle X-Ray and Neutron Scattering, $1^{\text {st }}$ ed: Springer: New York, 1987.

46. J. B. Hayter, J. Penfold, Determination of Micelle Structure and Charge by Neutron Small-Angle Scattering, Colloid Polym. Sci 261 (1983) 1022-1030, https://doi.org/10.1007/BF01421709

47. G. Garg, P. A. Hassan, V. K. Aswal, S. K. Kulshreshtha, Tuning The Structure Of SDS Micelles By Substituted Anilinium Ions, J. Phys. Chem. B 109 (2005) 1340-1346, https://doi.org/ 10.1021/jp0472663

48. P. A. Hassan, G. Fritz, E.W. Kaler, Small Angle Neutron Scattering Study of Sodium Dodecyl Sulfate Micellar Growth Driven by Addition of A Hydrotropic Salt, J. Colloid Interface Sci 257 (2003) 154-162, https://doi.org/10.1016/S0021-9797(02)00020-6 
49. P. A. Hassan, S. R. Raghavan, E. W. Kaler, Microstructural Changes in SDS Micelles Induced by Hydrotropic Salt, Langmuir 18 (2002) 2543-2548, https://doi.org/ 10.1021/la011435i

50. P. A. Hassan, S. N. Sawant, N. C. Bagkar, J. V. Yakhmi, Polyaniline Nanoparticles Prepared in Rodlike Micelles, Langmuir 20 (2004) 4874-4880, https://doi.org/ 10.1021/la0498096

51. C. Tanford, Micelle Shape and Size, J. Phys. Chem 76 (1972) 3020-3024, https://doi.org/ 10.1021/j100665a018

52. Y. Geng, L. S. Romsted, S. Froehner, D. Zanette, L. J. Magid, I. M. Cuccovia, H. Chaimovich, Origin of the Sphere-to-Rod Transition in Cationic Micelles with Aromatic Counterions: Specific Ion Hydration in the Interfacial Region Matters, Langmuir 21 (2005) 562-568, https://doi.org/ 10.1021/la0478954

53. K. Bijma, M. J. Blandamer, J. B. F. N. Engberts, Effect of Counterions and Headgroup Hydrophobicity on Properties of Micelles Formed by Alkylpyridinium Surfactants. 2. Microcalorimetry, Langmuir 14 (1998) 79-83, https://doi.org/ 10.1021/la970216n

54. T. Imae, SANS Investigation Of Supramolecular Assemblies Constructed In Aqueous Alkyldimethylamine Oxide Solutions With Organic Additives. Colloids Surf., $\quad$ A $109 \quad$ (1996) 291-304, https://doi.org/ https://doi.org/10.1016/0927-7757(95)03462-5

55. T. Imae, M. Kakitani, M. Kato, M. Furusaka, Effect of Organic Additives or Counterions on the Supramolecular Assembly Structures Constructed by Amphiphiles. A Small-Angle Neutron Scattering Investigation, J. Phys. Chem 100 (1996) 20051-20055, https://doi.org/ 10.1021/jp962127+ 
56. K. Yurekli, Mitchell, C. A.; Krishnamoorti, R., Small-Angle Neutron Scattering from Surfactant-Assisted Aqueous Dispersions of Carbon Nanotubes, J. Am. Chem. Soc 126 (2004) 9902-9903, https://doi.org/10.1021/ja047451u

57. C. Tanford, The Hydrophobic Effect: Formation of Micelles and Biological Membranes $2^{\text {nd }}$ ed: Wiley: New York, 1980.

58. K. Nawamawat, J. T. Sakdapipanich, C. C. Ho, Y. Ma, J. Song, J. G. Vansco, Surface Nanostructure of Hevea Brasiliensis Natural Rubber Latex Particles, $\begin{array}{lllll}\text { Colloids } & \text { Surf., } & \text { A } & 390 & \text { (2011) }\end{array}$ https://doi.org/10.1016/j.colsurfa.2011.09.021

59. C. N. Rochette, J. J. Crassous, M. Drechsler, F. Gaboriaud, M. Eloy, B. de Gaudemaris, J. F. L. Duval, Shell Structure of Natural Rubber Particles: Evidence of Chemical Stratification by Electrokinetics and Cryo-TEM, Langmuir 29 (2013) 14655-14665, https://doi.org/ 10.1021/la4036858

60. A. B. Suriani, M. D. Nurhafizah, A. Mohamed, A. K. Masrom, V. Sahajwalla, R. K. Joshi, Highly Conductive Electrodes of Graphene Oxide/Natural Rubber Latex-Based Electrodes by using a Hyper-Branched Surfactant, Mater. Des 99 (2016) 174-181, https://doi.org/10.1016/j.matdes.2016.03.067

61. J. C. Eriksson, S. Ljunggren, Model Calculations on the Transitions Between Surfactant Aggregates of Different Shapes, Langmuir 6 (1990) 895-904, https://doi.org/ 10.1021/la00095a002

62. B. Halle, M. Landgren, B. Jönsson, The Shape of Ionic Micelles, $\begin{array}{llll}\text { J. } & \text { Phys. (Paris) } & 49 & \text { (1988) }\end{array}$ https://doi.org/10.1051/jphys:019880049070123500 
63. S. May, A. Ben-Shaul, Molecular Theory of the Sphere-to-Rod Transition and the Second CMC in Aqueous Micellar Solutions, J. Phys. Chem. B 105 (2001) 630-640, https://doi.org/ 10.1021/jp003021o

64. D. Myers, Surfaces, Interfaces, and Colloids. $2^{\text {nd }}$ ed: Wiley-Vch: New York, 1999.

65. K. Spyrou, M. Calvaresi, E. K. Diamanti, T. Tsoufis, D. Gournis, P. Rudolf, F. Zerbetto, Graphite Oxide and Aromatic Amines: Size Matters, Adv. Funct. Mater. 25 (2015) 263-269, https://doi.org/10.1002/adfm.201402622

66. L. M. Woods, Ş. C. Bădescu, T.L. Reinecke, Adsorption of Simple Benzene Derivatives

on Carbon

Nanotubes, Phys. Rev. B 75 (2007) 155415, https://doi.org/10.1103/PhysRevB.75.155415

67. R. Bari, G. Tamas, F. Irin, A. J. A. Aquino, M. J. Green, E. L.Quitevis, Direct Exfoliation of Graphene in Ionic Liquids with Aromatic Groups, Colloids Surf., A 463 (2014) 63-69, https://doi.org/10.1016/j.colsurfa.2014.09.024 


\section{Table 1}

Surfactants used in this study

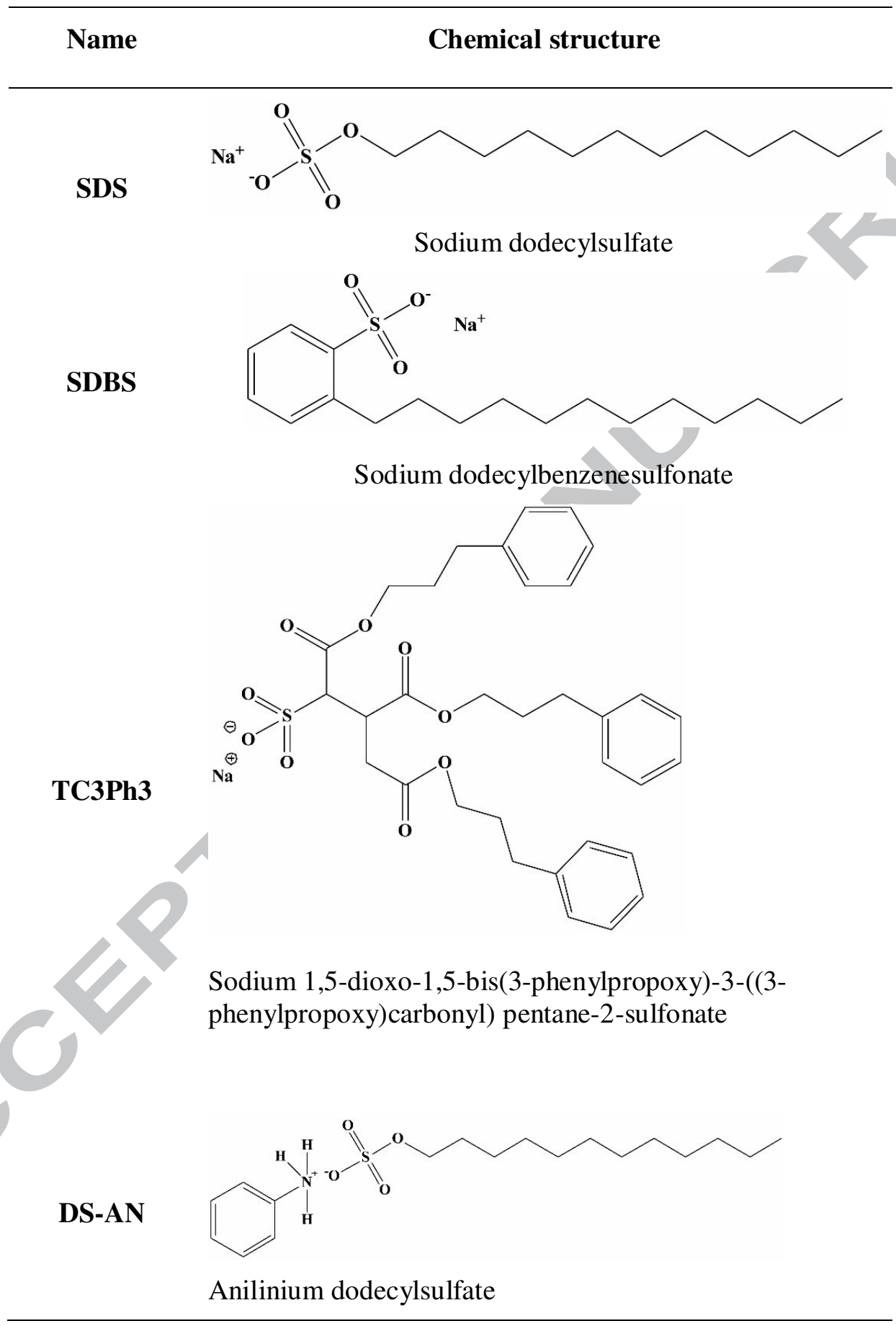




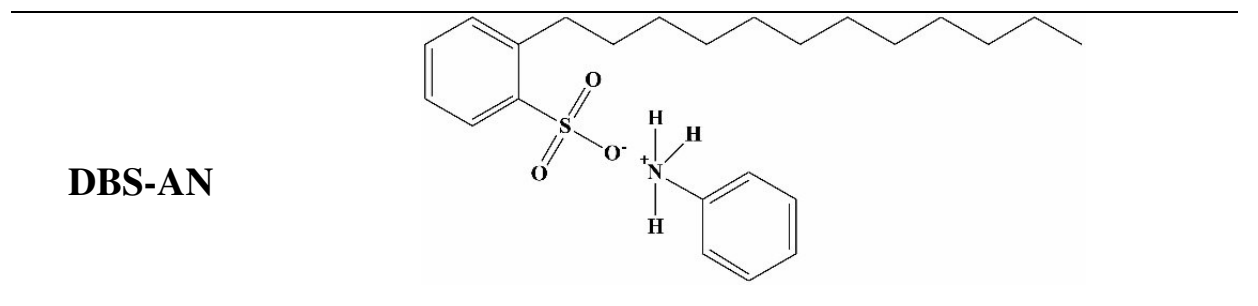

Anilinium dodecylbenzenesulfonate

\section{TC3Ph3-AN}

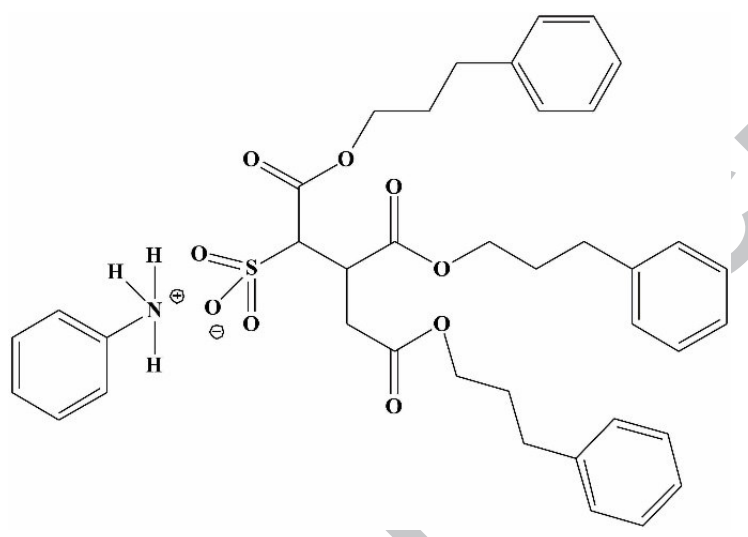

Anilinium1,5-dioxo-1,5-bis(3-phenylpropoxy)-3-((3phenylpropoxy)carbonyl) pentane-2-sulfonate

\section{Table 2}


Electrical conductivities of GNP/NRL composites stabilized by anilinium-bearing surfactants

\begin{tabular}{cccccc}
\hline & \multicolumn{5}{c}{ Surfactant concentration $(\mathbf{M})$} \\
\cline { 2 - 6 } Surfactant & $\mathbf{0 . 0 0 8}$ & $\mathbf{0 . 0 1 2}$ & $\mathbf{0 . 0 1 6}$ & $\mathbf{0 . 0 2 0}$ & $\mathbf{0 . 0 2 4}$ \\
\cline { 2 - 6 } & \multicolumn{5}{c}{ Electrical conductivity of nanocomposites $\left(\mathbf{S ~ c m}^{-1}\right)$} \\
\cline { 2 - 6 } TC3Ph3-AN & $1.08 \times 10^{-2}$ & $1.28 \times 10^{-4}$ & $3.59 \times 10^{-5}$ & $5.96 \times 10^{-6}$ & $1.60 \times 10^{-5}$ \\
DBS-AN & $1.54 \times 10^{-6}$ & $5.74 \times 10^{-6}$ & $1.14 \times 10^{-5}$ & $3.86 \times 10^{-5}$ & $2.11 \times 10^{-4}$ \\
DS-AN & $1.03 \times 10^{-6}$ & $5.69 \times 10^{-6}$ & $1.50 \times 10^{-4}$ & $6.00 \times 10^{-6}$ & $3.45 \times 10^{-6}$ \\
& & & & & \\
\hline
\end{tabular}




\begin{tabular}{lcccc}
\hline Surfactant & $\zeta$-potential / & $\begin{array}{c}\text { No of } \\
\text { aromatic } \\
\text { rings in } \\
\text { headgroup }\end{array}$ & $\begin{array}{c}\text { No. of } \\
\text { aromatic } \\
\text { rings on } \\
\text { surfactant } \\
\text { chains }\end{array}$ & $\begin{array}{c}\text { Order of magnitude } \\
\text { of electrical } \\
\text { conductivity } \\
\text { enhancement }\end{array}$ \\
\hline DS-AN & $-45 \pm 1$ & 1 & - & $\sim 10$ \\
DBS-AN & $-63 \pm 8$ & 1 & 1 & $\sim 10$ \\
TC3Ph3-AN & $-99 \pm 7$ & 1 & 3 & $\sim 12$ \\
\hline
\end{tabular}

\section{Table 3}

Zeta potential value of GNP-stabilized surfactants dispersion and the relationship to surfactant headgroup modification and electrical conductivity enhancement of nanocomposites 


\section{Table 4}

Model fit parameters for the SANS data (Dimensions in Angstrom)

\begin{tabular}{|c|c|c|c|c|c|c|}
\hline Surfactant & Model & $\begin{array}{l}\boldsymbol{R}_{\text {cylinder }} \\
(\AA)\end{array}$ & $\begin{array}{l}\text { Length }^{\mathbf{b}} \\
(\AA)\end{array}$ & $\begin{array}{l}L^{\mathrm{c}} \\
(\stackrel{\AA}{\mathbf{A}})\end{array}$ & $\begin{array}{l}D^{\mathbf{c}} \\
(\AA)\end{array}$ & $M^{\mathfrak{c}}$ \\
\hline \multicolumn{7}{|c|}{ Surfactant solution } \\
\hline DS-AN & Cylinder & 14.0 & 168.0 & - & - & - \\
\hline DB & Lamellar & - & - & 45.0 & - & - \\
\hline $\mathrm{TC}$ & Lamellar stack & - & - & 108.0 & 35.0 & 11.0 \\
\hline \multicolumn{7}{|c|}{ Surfactant + GNP dispersion } \\
\hline DS-AN & Cylinder & 13.0 & 195.0 & - & - & - \\
\hline DBS-AN & $\begin{array}{l}\text { Lamellar stack } \\
\text { paracrystal }\end{array}$ & - & - & 56.0 & 39.0 & 2.0 \\
\hline TC3Ph3-AN & $\begin{array}{l}\text { Lamellar stack } \\
\text { paracrystal }\end{array}$ & - & - & 120.0 & 55.0 & 37.0 \\
\hline
\end{tabular}


Fig.1. Electrical conductivities of NRL and GNP/NRL composites with anilinium and sodium-bearing surfactants as stabilizers. The error bars are given for three experimental measurements

Fig. 2. FESEM images of GNP/NRL with: (a and a') DS-AN, (b and b') DBS-AN, and (c and c') TC3Ph3-AN

Fig. 3. HRTEM micrographs GNP/NRL/TC3Ph3-AN nanocomposites

Fig 4. Raman spectroscopy of GNP (a) and nanocomposites: (b) GNP/NRL/DS-AN, (c) GNP/NRL/DBS-AN, (d) GNP/NRL/TC3Ph3-AN 
Fig. 5. Relationship between zeta potential, number of aromatic groups on the surfactant molecule and order of magnitude enhancement in nanocomposite electrical properties stabilized by anilinium and sodium surfactants.

Fig. 6. SANS profiles of DS-AN, DBS-AN, and TC3Ph3-AN in (a) surfactant solutions and (b) GNP dispersions. [Surfactant] $=0.03 \mathrm{M}$ and $\mathrm{T}=25^{\circ} \mathrm{C}$. Lines are model fits for cylindrical micelles (with Hayter-Penfold $S(Q)$ ) and lamellar model. Characteristic error bars are shown for the lowest intensity samples

Fig. 7. Schematic illustration of TC3Ph3-AN self-assembled structure

\section{Fig. 1.}

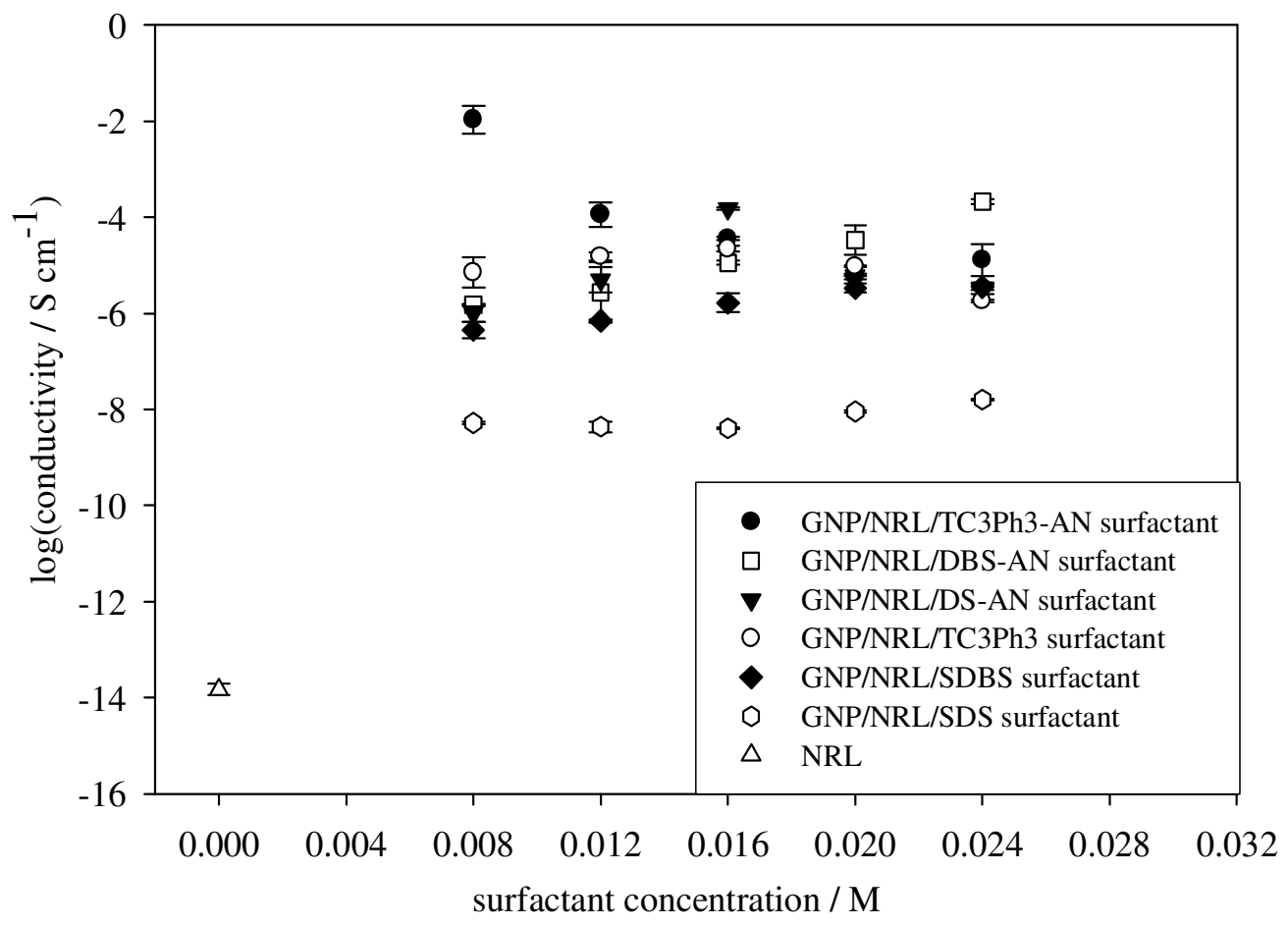


Fig. 2.
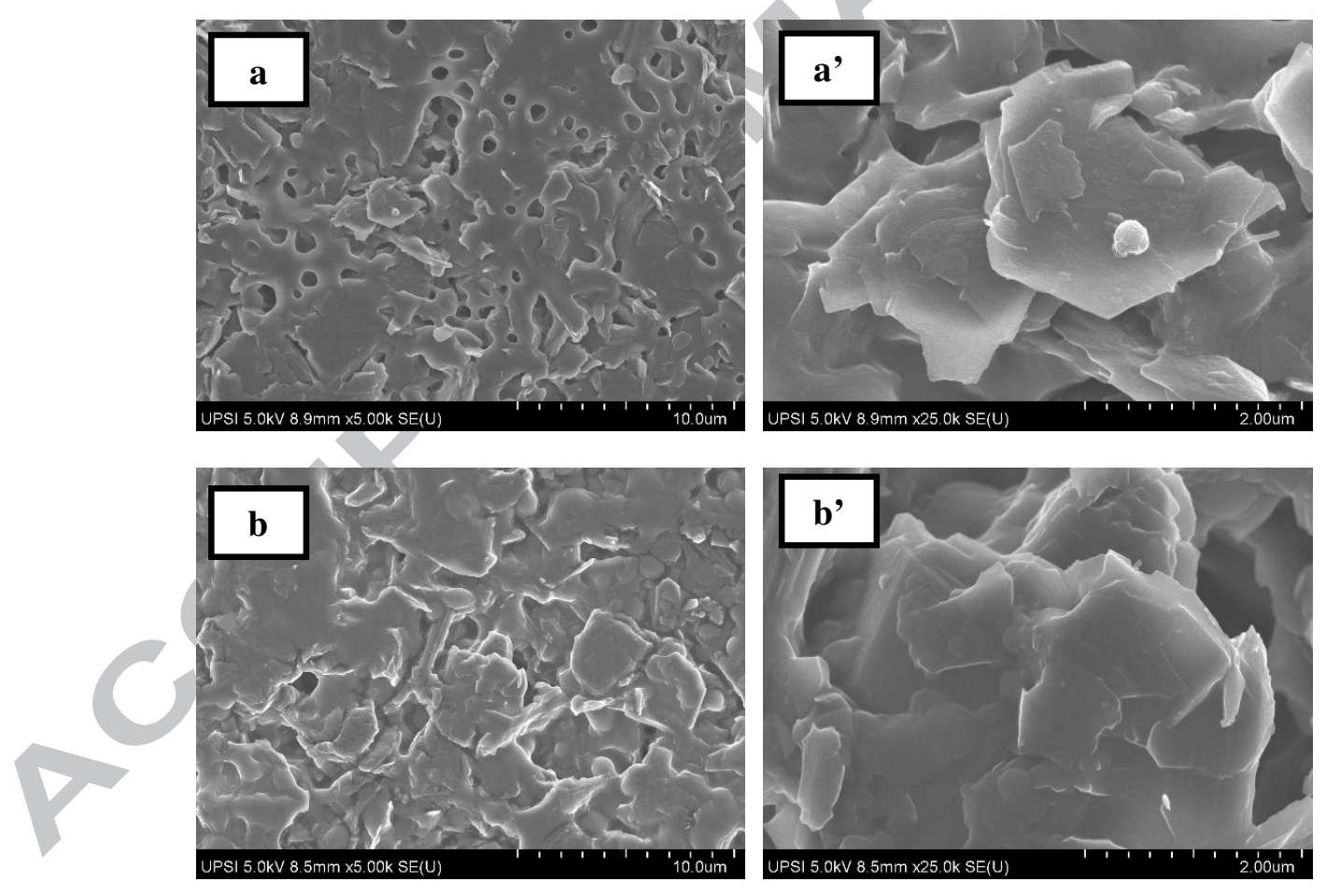


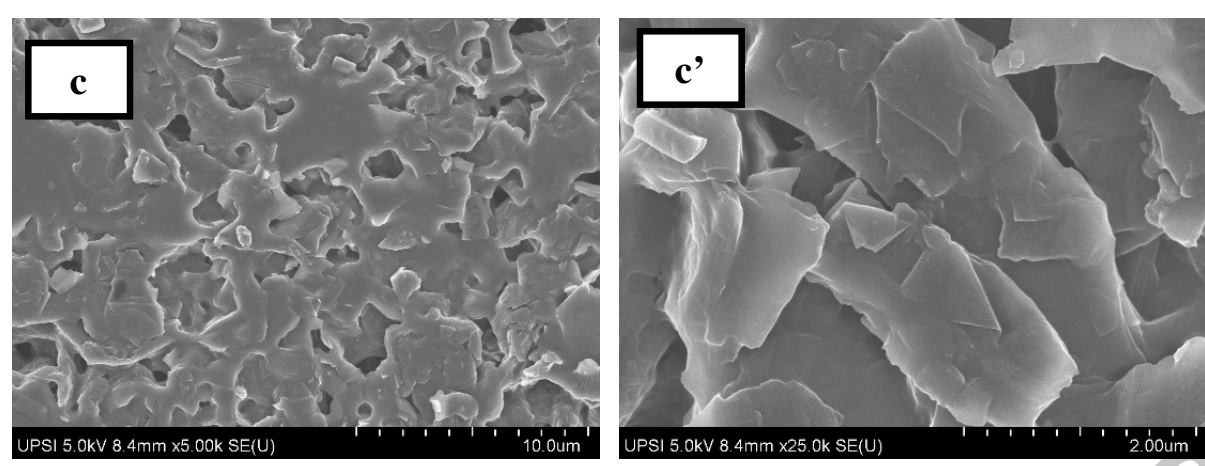

Fig. 3.

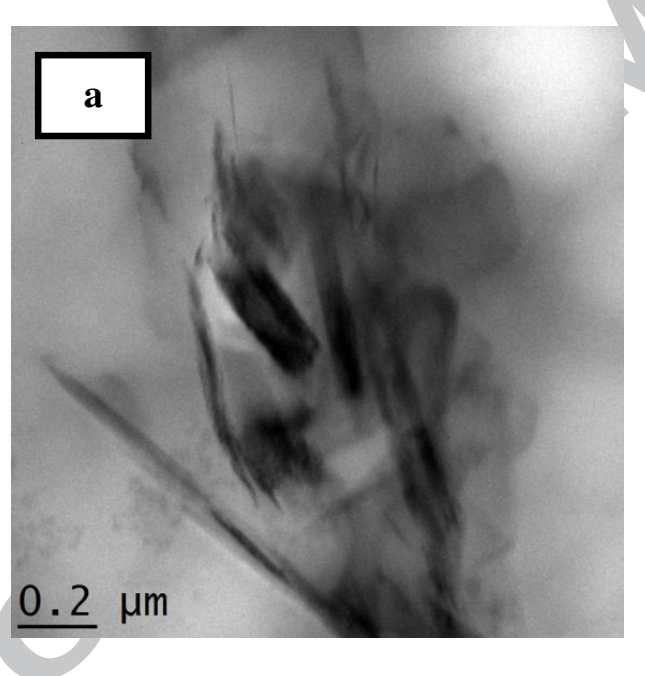



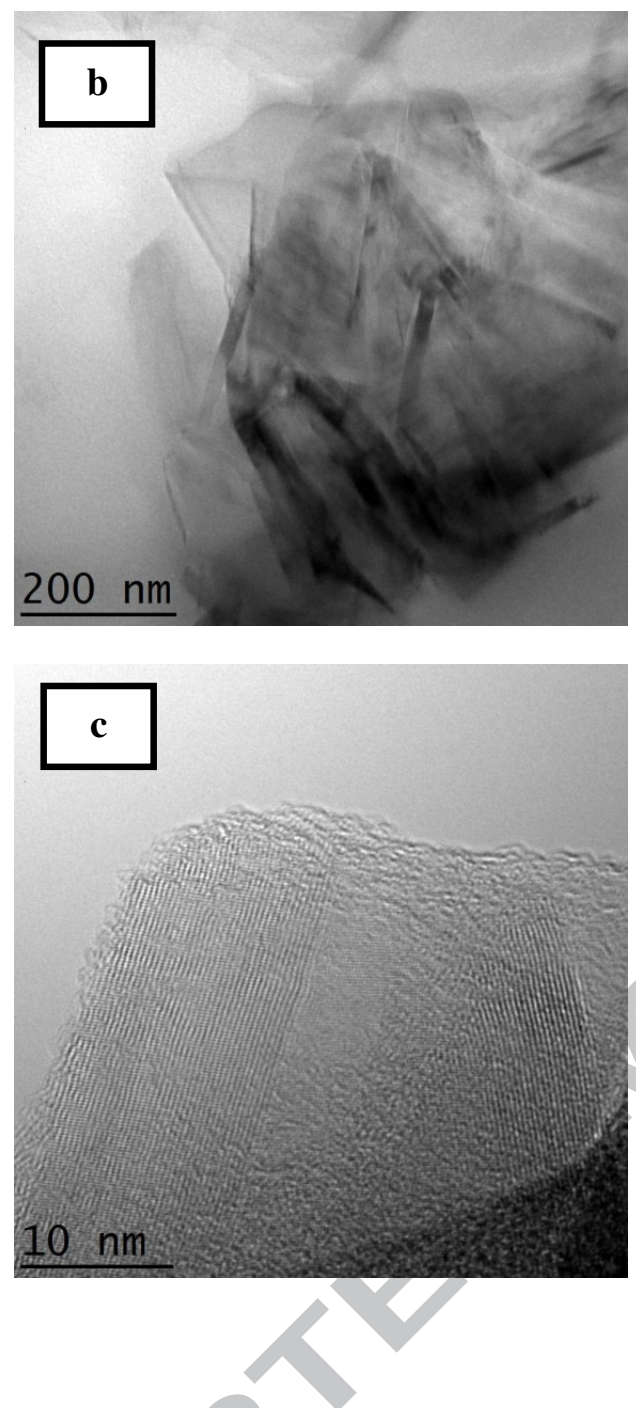

Fig. 4. 


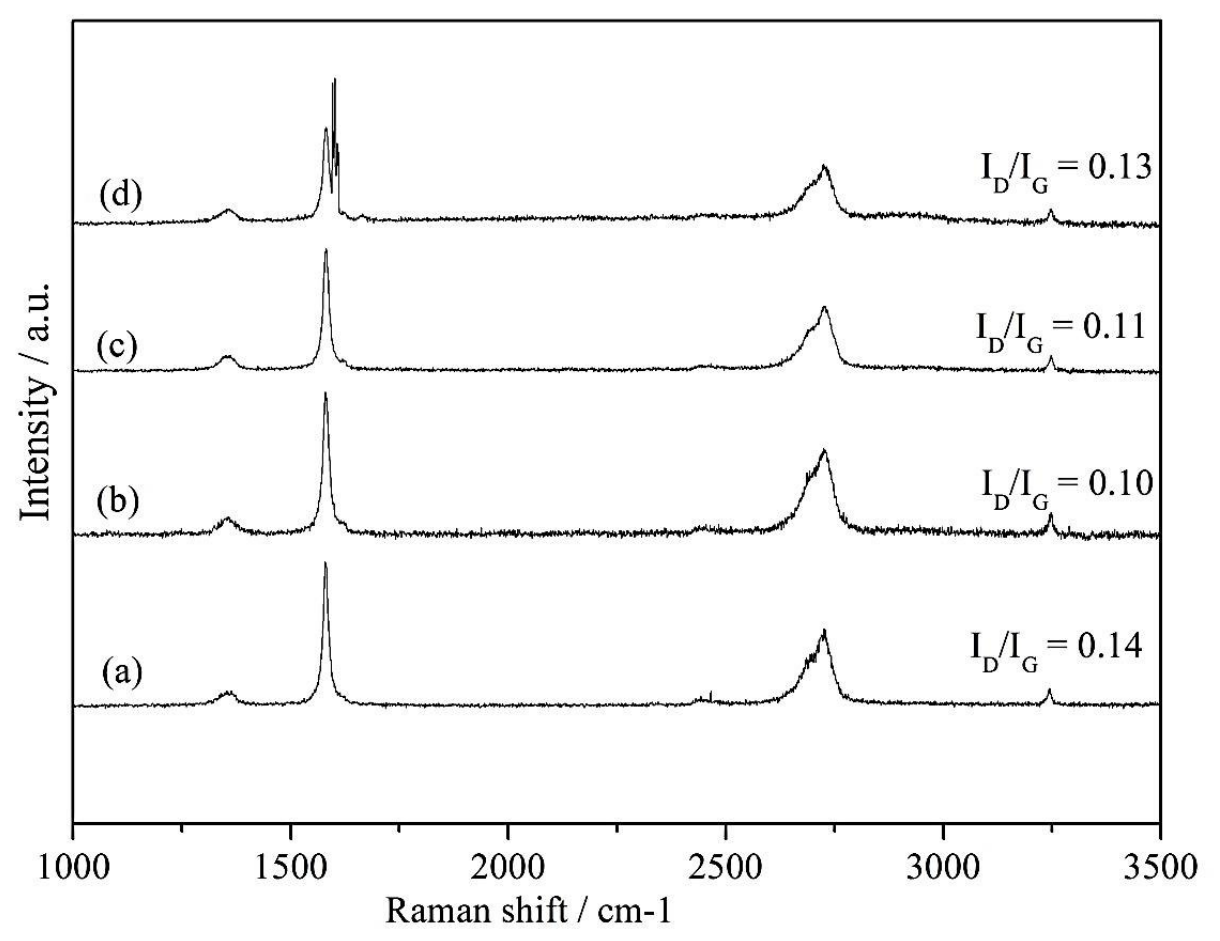

Fig. 5. 


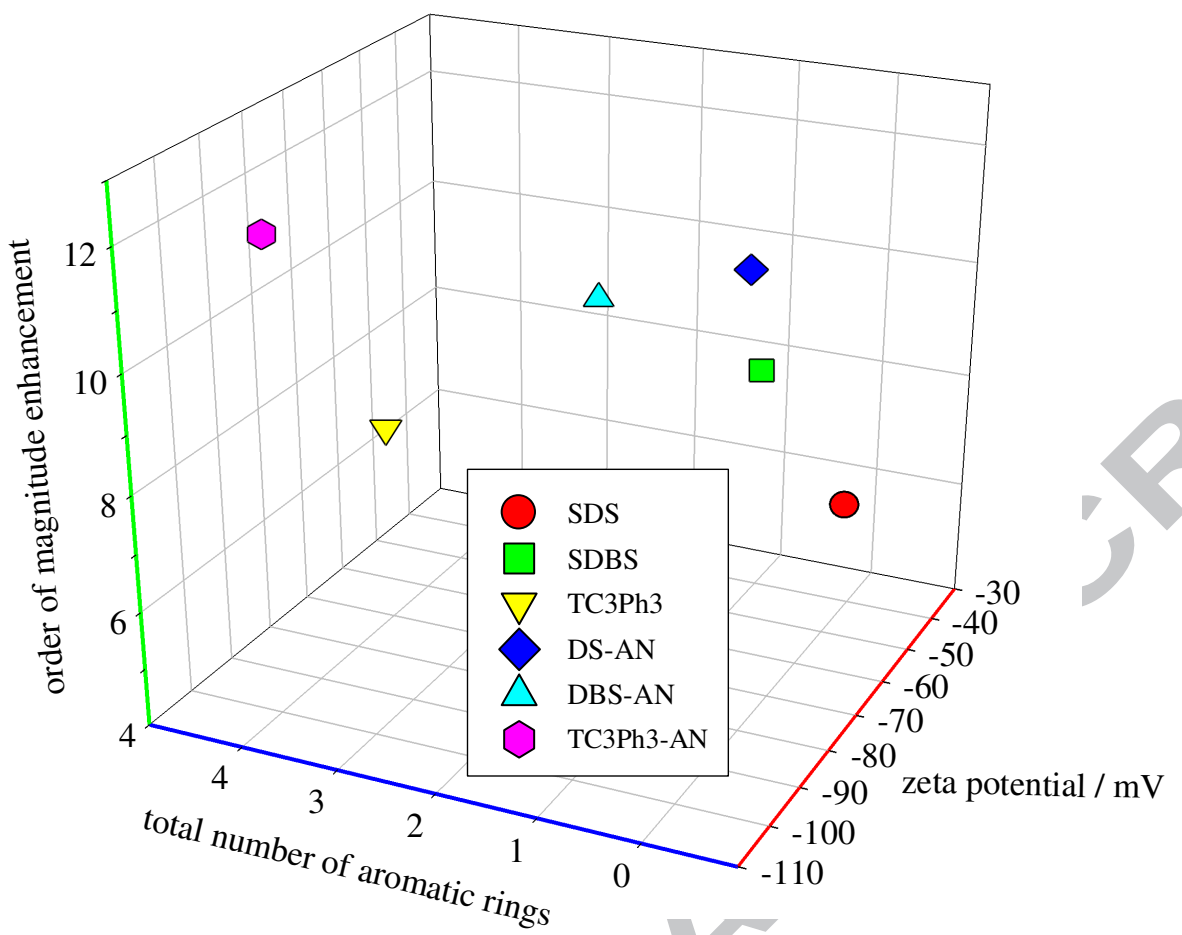

Fig. 6. 

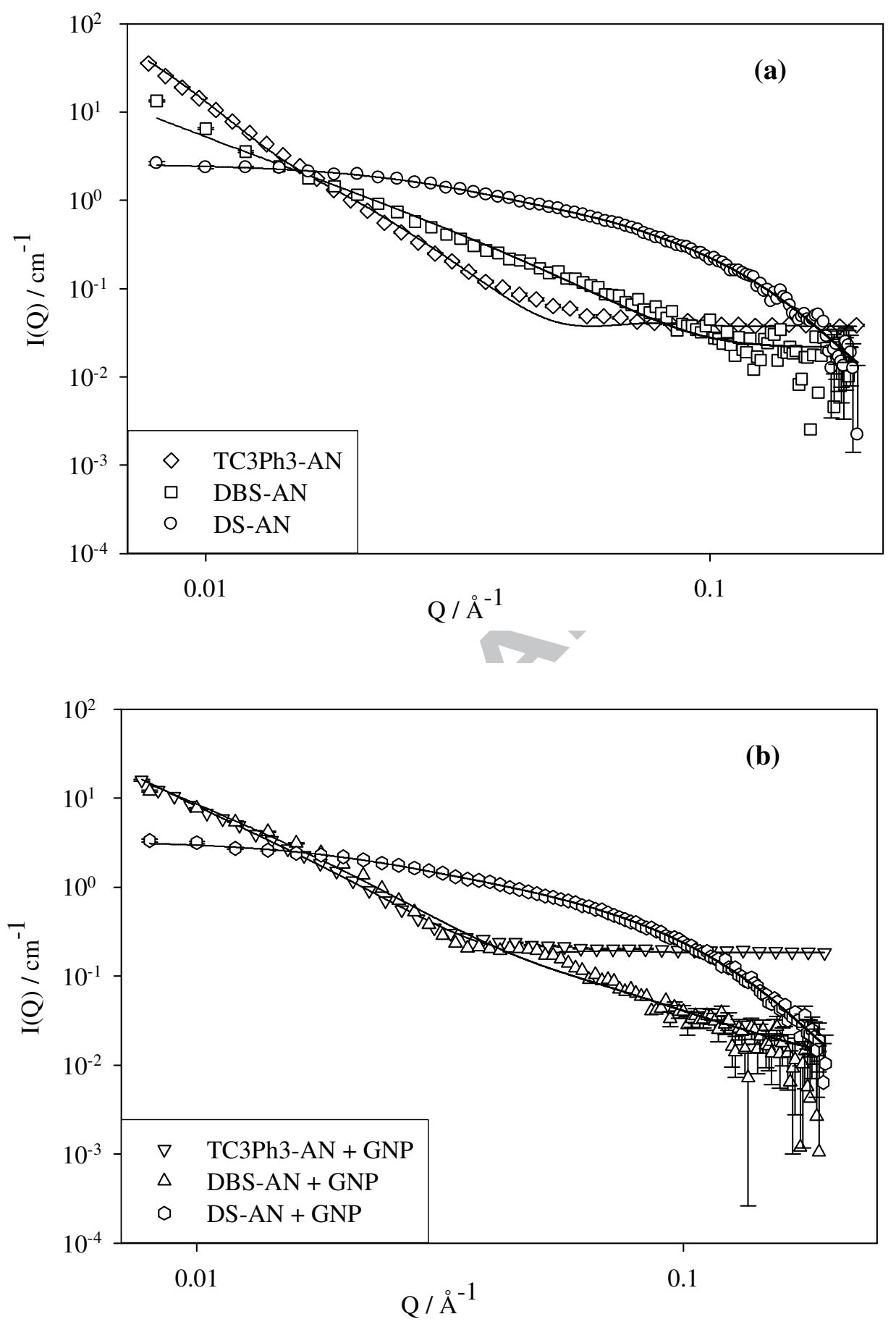
Fig. 7.

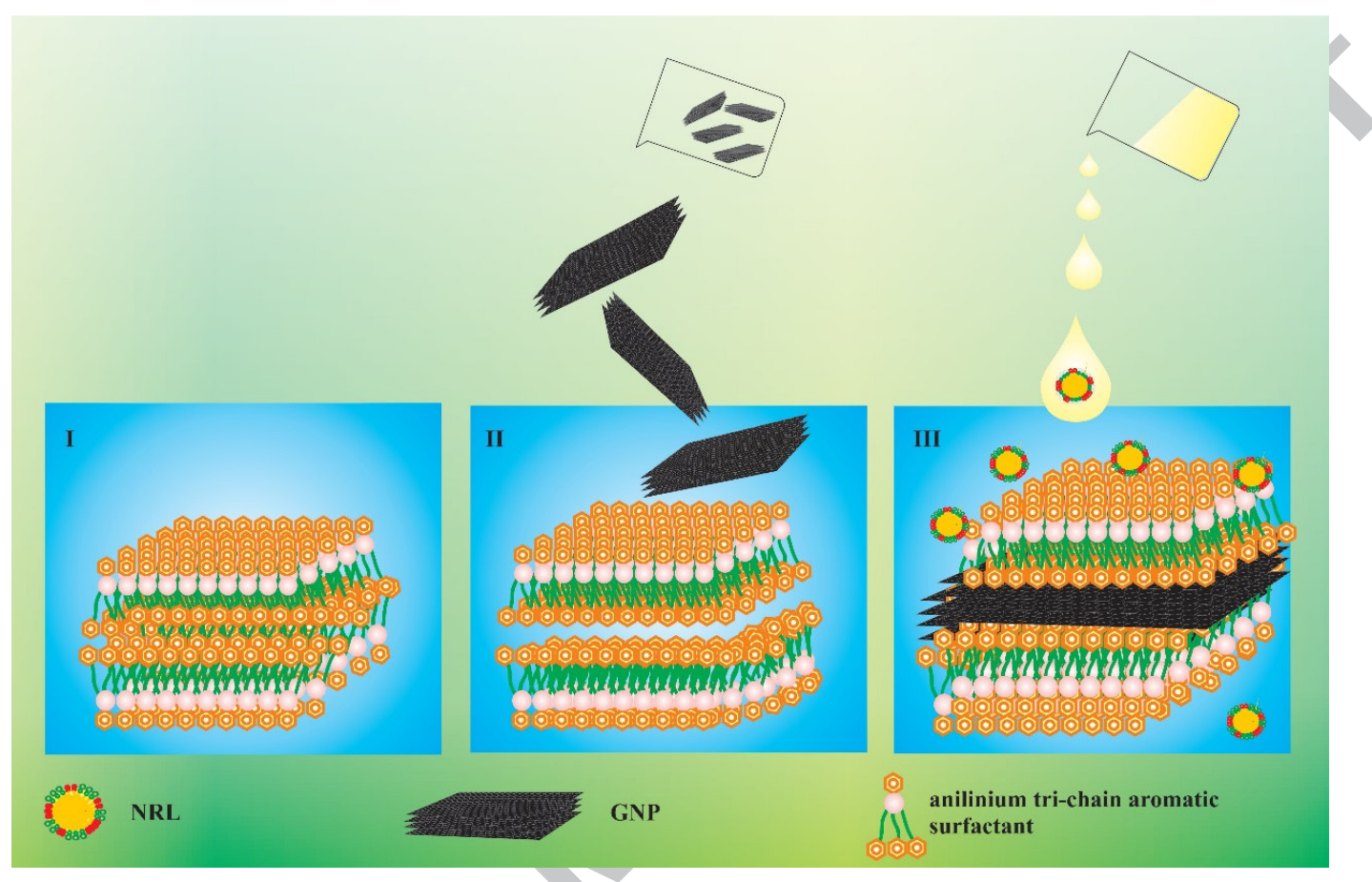

